\title{
APORTES A LA ECOLOGÍA ISOTÓPICA: INFORMACIÓN ACTUAL Y SISTEMAS DE REGADÍO ARQUEOLÓGICOS EN LA MICRORREGIÓN DE ANTOFAGASTA DE LA SIERRA (PROVINCIA DE CATAMARCA, ARGENTINA)
}

\section{CONTRIBUTIONS TO ISOTOPE ECOLOGY: CURRENT INFORMATION, AND ARCHAEOLOGICAL IRRIGATION SYSTEMS IN ANTOFAGASTA DE LA SIERRA MICROREGION (CATAMARCA PROVINCE, ARGENTINA)}

\author{
Violeta A. Killian Galván ${ }^{1}$ y Pedro Salminci \\ 1CONICET/ Instituto de Geocronología y Geología Isotópica (INGEIS-CONICET). UBA - Pabellón INGEIS, \\ Ciudad Universitaria. CABA - E-mail: violetakillian@gmail.com \\ 2. Instituto Nacional de Antropología y Pensamiento Latinoamericano - E-mail: pedrosalminci@yahoo.com.ar
}

Presentado el: 15/05/2013 - Aceptado el: 10/01/2014

\begin{abstract}
Resumen
El siguiente trabajo presenta los primeros avances en los estudios isotópicos de plantas cultivadas para la Microregión de Antofagasta de la Sierra. Los mismos se realizaron dentro de un proyecto de investigación interesado en evaluar la evolución del consumo de Zea mays desde su introducción en la dieta hasta el período de contacto hispano-indígena. Este trabajo apunta a entender el efecto de las prácticas de abono y riego en los valores $\delta^{13} \mathrm{C}$ y $\delta^{15} \mathrm{~N}$ de plantas cultivadas con diferentes patrones fotosintéticos. Para ello se procedió a la recolección en huertas familiares ubicadas a diferentes altitudes dentro de la Microregión. La recolección se vio acompañada por la entrevista a los propietarios detallando no solo los pasos que comprenden la producción, sino el destino de las cosechas. Nuestro resultados apuntan a un rango amplio de valores $\delta^{15} \mathrm{~N}$ para el maiz, con especimenes notoriamente enriquecidos, siendo coherentes con aquellos valores observados en tejidos humanos en Puna.
\end{abstract}

Palabras claves: Zonas áridas, abono, riego, isótopos estables 


\begin{abstract}
This paper shows the first advances in isotopic studies of cultivated plants for the micro region of Antofagasta de la Sierra. They were performed within a research project interested in assessing the evolution of Zea mays consumption since its introduction in diet until the Spanish contact. The aim of this paper is oriented to understand the effects of fertilizers and irrigation practices in $\delta^{13} \mathrm{C}$ and $\delta^{15} \mathrm{~N}$ values of cultivated plants with different photosynthetic pathways. In order to do this, we have harvested specimens from family farms located at different altitudes within the microregion. The collection was accompanied by an interview with the owners of the fields detailing not only the steps that comprise the production, but the destination of the crops. This study have allowed to generate new hypotheses about the importance of plant as a component of the Puna's diets and how they could have become relevant during periods of increased agricultural intensification and extensification. Our results point to a wide range of $\delta^{15} \mathrm{~N}$ values in maize, with markedly enriched specimens, being coherent with those values seen in human tissues from Puna.
\end{abstract}

Key words: Arid zones, fertilizer, irrigation, stable isotopes

\title{
Introducción
}

Luego de más de una década de estudios paleodietarios mediante el uso de isótopos estables en sociedades agropastoriles del Noroeste argentino (Olivera y Yacobaccio 2002, Aranibar et al. 2007, Pérez y Killian Galván 2012, Killian Galván et al. 2012, Killian Galván y Samec 2012) entendemos que debemos avanzar en el grado de especificidad de nuestras interpretaciones, ampliando nuestro conocimiento sobre las fuentes de variabilidad en los valores isotópicos. En particular, en este trabajo haremos foco en los comportamientos humanos que pueden repercutir en los valores isotópicos de las especies vegetales domésticas consumidas.

En el caso de zonas áridas, el cultivo posee como principal restricción al agua y sólo es posible, mediante una dependencia total o parcial del riego. Sin embargo, en muchas ocasiones, este no es el único limitante. Las características químicas del suelo también restringen el crecimiento adecuado de plantas cultivadas. Este es el caso del área puneña de Antofagasta de la Sierra (Catamarca) donde se encuentran suelos con escaso desarrollo, catalogados dentro de los entisoles (Tchilinguirian y Olivera 2000). No obstante sobre este tipo de suelos se hallaron grandes extensiones de campos de cultivo prehispánicos (Olivera et al. 2003-2005,) y una menor proporción de tierras cultivadas en la actualidad. Estas circunstancias indican que las insuficiencias del suelo fueron y son superadas mediante algún tipo de prácticas de fertilización que dan a los cultivos los nutrientes necesarios para su adecuado desarrollo.

Si nuestro interés es modelar la predominancia de ciertos ítems alimenticios sobre otros en las dietas de los individuos que habitaron la microrregión en el pasado, la capacidad productiva es un aspecto importante a considerar. Debido a ello, iniciamos una línea de investigación que relaciona las prácticas de riego y abono de la tierra con las relaciones isotópicas que utilizamos para inferir patrones paleodietarios. Nuestro principal interés es evaluar si estas prácticas repercuten en los valores de $\delta^{15} \mathrm{~N}$ de las plantas cultivadas y por lo tanto de los valores finales de los tejidos humanos (Finucane 2007).

Por lo tanto, en este trabajo revisaremos la relación entre el uso de fertilizantes y el riego y sus consecuencias en la ecología isotópica del área. Esto se realiza en el marco de las primeras observaciones etnoarqueológicas sobre prácticas de siembra realizadas 
recientemente en diferentes sectores eco-topográficos en Antofagasta de la Sierra. Con este objetivo, se muestrearon especímenes de Zea mays, Chenopodium quinoa y Solanum tuberosum, confiando que a partir de ellos, tendremos mayores elementos a la hora de interpretar los patrones paleodietarios surgidos del análisis de isótopos estables en el registro óseo humano. Sobre todo en las inferencias que realizamos a partir de valores altos en $\delta^{15} \mathrm{~N}$ de colágeno en dicho registro.

\section{Descripción del área}

La microrregión de Antofagasta de la Sierra (Catamarca, Argentina) es un desierto de altura, ubicado entre los 3300 y $4400 \mathrm{msnm}$, y perteneciente a la Puna meridional argentina (Figura 1). Posee un clima árido, bajas precipitaciones (con medias anuales inferiores a los $130 \mathrm{~mm}$ y un aumento de la imprevisibilidad de las mismas durante la estación más seca), gran amplitud térmica, una temperatura media anual de $10^{\circ}$, siendo enero el mes más cálido $\left(27^{\circ}\right)$ y julio el más frío $\left(-6^{\circ}\right)$ y la evapotranspiración anual media llega a $550 \mathrm{~mm}$ (García y Rolandi 1999, Grana 2013, Tchilinguirian 2008). Dadas las temperaturas señaladas, la longitud de la estación de crecimiento de las plantas cultivadas es de solo 5 meses, desde el mes de noviembre hasta abril (Tchilinguirian y Olivera 2012). No obstante, esta aridez se encuentra mitigada por las aguas de la cuenca endorreica y permanente del Río Punilla, la cual permite la formación de ecosistemas aptos para la vida de plantas, fauna y el desarrollo de sociedades humanas, de las cuales se han registrado evidencias a partir de los ca. 10000 años AP (Martínez 2003). A este río, se añaden Las Pitas, Los Colorados y Miriguaca, pero todos con un caudal mucho menor (Tchilinguirian y Olivera 2012) Todos ellos poseen baja conductividad (200 a 400 microohms) y bajos valores de RAS (Relación Absorción de Sodio 0.75-1.3) (Tchilinguirian y Olivera 2012). La región no se caracteriza por poseer nieves permanentes y el Río Punilla no incrementa sus caudales durante los deshielos de primavera y verano (Tchilinguirian 2008). Resulta importante señalar que las aguas factibles para el riego se clasifican como dulces, de bajo contenido de sodio importante para el desarrollo de la vegetación (Tchilinguirian 2008, Tchilinguirian y Olivera 2012). La región posee una vegetación típicamente puneña, con ausencia de vegetación arbórea y presencia de queñoa (Polylepis tomentella), churqui (Prosopis ferox) y arbustos pequeños (Paoli et al. 2002). Dadas las características climáticas se conforman asociaciones vegetales de estepa arbustiva, estepa arbustiva-graminosa y estepa graminosa abiertas y discontinuas. En cambio en las zonas con más agua, son frecuentes los pastizales de gramíneas (Paoli et al. 2002).

La microrregión se compone de tres sectores eco-topográficos con posibilidades para la instalación humana:

1) el fondo de cuenca (3300-3550 msnm), es una zona amplia y plana donde se concentra la mayor parte de los recursos hídricos y biomasa vegetal en forma de vegas, también existe un pequeño ambiente lacustre sobre los espejos de agua terminales de la cuenca. Esta zona es la más apta para el desarrollo agrícola y fue propuesta como área residencial dispersa ocupada anualmente y dedicada a múltiples actividades en donde se destacan la ganadería y la agricultura;

2) los sectores intermedios (3550-3800 msnm), son zonas más estrechas, que en muchos casos constituyen las quebradas de los ríos tributarios del Punilla, con vegas más acotadas, aptas para la agricultura y el pastoreo, propuestas como áreas residenciales similares a las anteriores pero más pequeñas y menos densamente pobladas; 


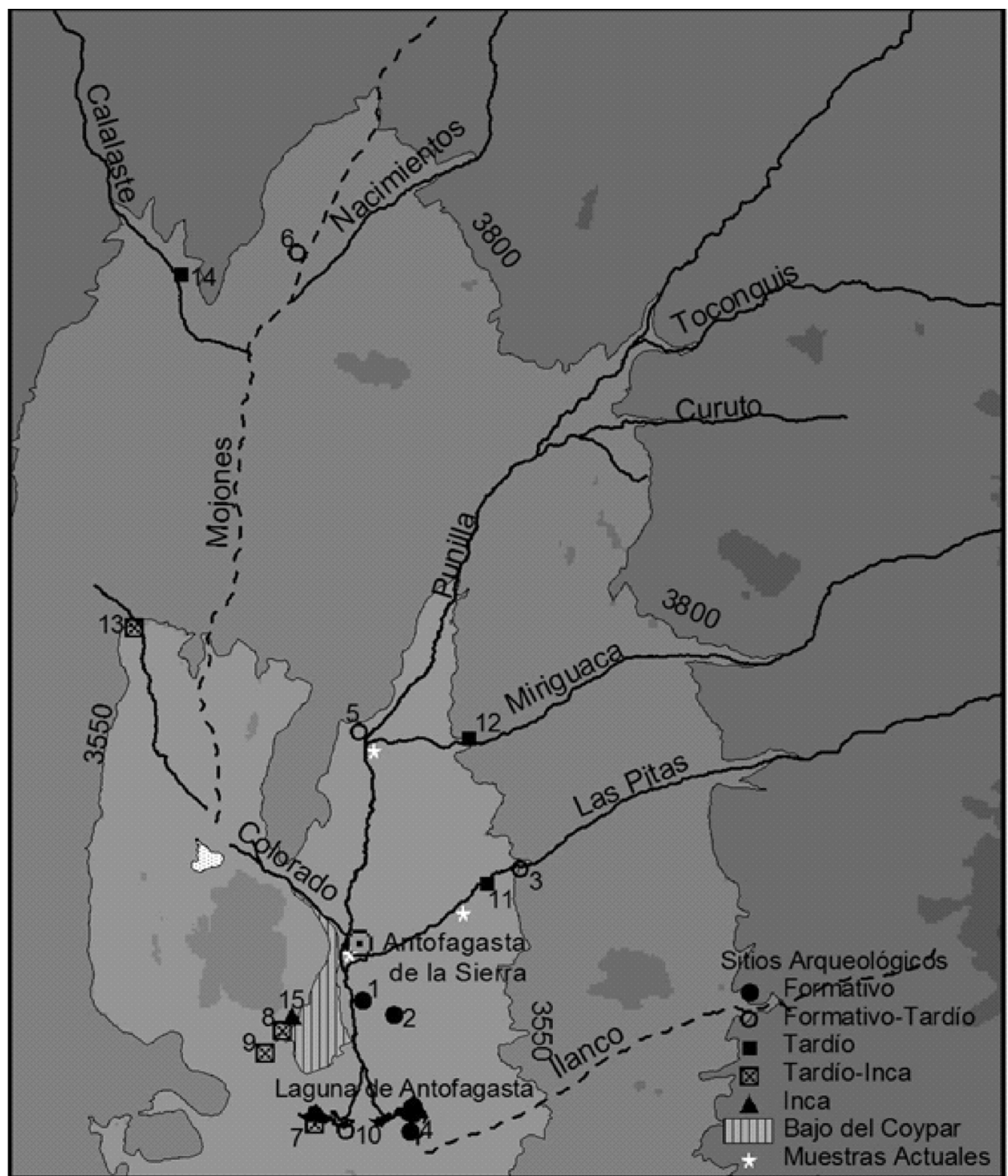

Figura 1: Microrregíon de Antofagasta de la Sierra. Sitios arqueológicos: 1. Casa Chávez Montículos; 2. Casa Chávez Lomas; 3. Punta de la Peña; 4. Volcán; 5. Las Juntas; 6. Corral Grande; 7. La Alumbrera, 8. Bajo del CoyparII; 9. Qda. de Petra; 10. Arroyo Seco; 11. Peñas Coloradas III; 12. Corral Alto; 13. Campo Cortaderas; 14. Punta Calalaste; 15. Coyparcito.

3) por último, la alta puna (3800 y $4600 \mathrm{msnm}$ ), está caracterizada por vegas y extensas zonas de pajonal, siendo el clima sólo apto para actividades estacionales de pastoreo y a caza (García et al. 2002b).

\section{Antecedentes arqueológicos}

La secuencia cronológica revelada por las investigaciones arqueológicas, indica que la agricultura se hizo presente en la región en el Período Formativo hacia los ca. 3000 años AP, luego de un período inicial de unos 5500 años de economías dedicadas principalmente 
a la caza, y de otros 1500 años de economías especializadas en el pastoreo de camélidos (Yaccobacio et al. 1994, Achero 2000). Durante este período comienza a darse un uso diferencial del espacio microrregional estructurado en los tres sectores eco-topográficos con posibilidades para la instalación humana ya mencionados.

En sus momentos iniciales, la agricultura tuvo una importancia menor en la economía y la dieta, haciéndose cada vez más relevante hasta llegar a un máximo a partir de los ca. 1000 años AP, en el Período Tardío, en asociación con sistemas de canalización y riego por inundación de parcelas que alcanzó unas 600 ha en el fondo de cuenca en el sitio Bajo del Coypar y otras 70 ha en varios sitios de los sectores intermedios (Tchilinguirian y Olivera 2012). Acompañando esta expansión e intensificación agrícola, se registran aumentos y concentraciones demográficas en asentamientos nucleados y fortificados particularmente en el fondo de cuenca en el sitio La Alumbrera (Olivera y Vigliani 2000/2002, Salminci 2010). Con la ocupación Inca, se amplió en un $10 \%$ esta superficie cultivada al elevar la línea de rigidez mediante una canalización sobre ladera con tecnología de pirca (Olivera y Vigliani 2000/2002; Tchilinguirian y Olivera 2012).

En cuanto a las especies cultivadas en épocas prehispánicas, aún se cuenta con pocas evidencias, sólo se han hallado restos de maíz, de distintas subespecies, en el sitio Quebrada de Petra (Olizewski y Olivera 2009), ubicado a $500 \mathrm{~m}$ de los campos de cultivo y a unos 2 $\mathrm{km}$ del asentamiento La Alumbrera, dentro de oquedades realizadas en rocas de ignimbrita en lo que parecen ser antiguos depósitos, fechados dentro del Período Tardío (Olivera y Vigliani 2000/2002).

Debido a la escasez de datos arqueológicos e históricos aún se desconoce en detalle el proceso social en el área luego de la conquista española y durante el período colonial (García et al. 2000), pero todo apunta a que se dio un colapso demográfico y un quiebre cultural incluyendo una ruptura en la tradición agrícola. Para el momento de la incorporación de la región al territorio argentino en el año 1901, su primer gobernador relata que el actual pueblo de Antofagasta de la Sierra estaba formado por unos pocos caseríos habitados por escasas familias dedicadas a la ganadería con una pequeña producción agrícola de 2 ha de alfalfa (Cerri 1903), una forrajera originaria del viejo mundo.

\section{Características actuales del manejo agrícola en el área}

En la actualidad, y si bien la ganadería de llamas, ovejas y cabras continúa siendo la principal actividad productiva, la agricultura se ha expandido llegando a cubrir unas 70 ha, gran parte de las cuales se ubican sobre los viejos campos prehispánicos de Bajo del Coypar (Figura 1). Investigaciones antropológicas indican que los cultivos son mantenidos a escala doméstica, siendo el principal la alfalfa, aunque también se cultivan alimentos como legumbres, hortalizas, quinoa, maíz y papa (García et al. 2002). Con una economía orientada a la ganadería, no se cuentan con una información sistematizada sobre volúmenes reproducción agrícola, ni tampoco las variedades de maíz que se cultivan (ver Paoli et al. 2002).

A pesar del quiebre postconquista y los fenomenales cambios culturales, particularmente en la actividad productiva que nos interesa, con la introducción de nuevas especies vegetales y animales, existe un puente que une las prácticas agrícolas prehispánicas con las actuales dando sustento y validez a la realización de investigaciones actualísticas 
como la que presentamos. Este puente es en esencia el clima y el ambiente que básicamente continúa teniendo las mismas características generales que en los últimos 2000 años e impone las mismas limitaciones a las prácticas productivas y probablemente soluciones similares.

En primer lugar la escasez de agua impone una agricultura bajo riego, la cual durante el pasado como en el presente depende de los mismos cursos de agua, cuyos volúmenes no parecen haber variado (Tchilinguirian 2008). Las técnicas de riego actuales son, en su mayoría, similares a las de tiempos prehispánicos: conducción de agua por gravedad a través de acequias y riego por inundación de parcelas rodeadas por elevaciones del terreno llamadas bordos (García et al. 2002a, Olivera y Tchilinguirian 2000).

En segundo lugar el ciclo agrícola está restringido a una sola estación, durante los meses más cálidos (septiembre-abril), las temperaturas del resto del año imposibilitan el cultivo durante el resto del año debido principalmente al congelamiento del agua de riego y de las raíces. Esto dificulta la consolidación de una economía basada exclusivamente en la agricultura, y sugiere que hasta en los momentos de mayor producción agrícola, durante los Períodos Tardío e Inca, la ganadería de camélidos no haya dejado de tener un rol de gran importancia.

Y en tercer lugar y más importante para el presente estudio es la falta de nutrientes de los suelos cultivados y la necesidad de fertilizar artificialmente los campos. Como mencionamos en la introducción gran parte de los suelos de los campos Bajo del Coypar pertenecen a la terraza alta del Río Punilla constituida por suelos de escaso desarrollo clasificados dentro de los entisoles (Olivera y Tchilinguirian 2000). No existen datos directos acerca de las técnicas de fertilización utilizadas en el pasado, pero es altamente probable que el uso de excremento animal haya sido la solución principal. En la actualidad, la práctica de abono con bosta animal ha sido descrita por García y colaboradores (2002a) donde los "corrales" de cabras y ovejas son utilizados alternativamente como rastrojos para así garantizar tierras abonadas en las siembras futuras. Como explicamos a continuación el uso de abono animal puede producir una alteración en la ecología isotópica de las plantas cultivadas y posteriormente en los valores isotópicos de los humanos que se alimentaron de las mismas.

A modo de resumen de lo establecido hasta aquí, la arqueología de Antofagasta de la Sierra revela una importancia creciente de la agricultura en la economía y la dieta a partir del Período Formativo, con un máximo durante el período Tardío e Inca. No obstante la ganadería continuó siendo de gran importancia en la economía y probablemente en la dieta. La relación entre la producción ganadera y la agrícola puede así, entenderse como simbiótica, en donde el excremento animal garantizaba los nutrientes necesarios para el crecimiento de los cultivos y a su vez, los subproductos no consumidos por el hombre pudieron ser utilizados como forraje para ganado. A pesar del quiebre del proceso histórico entre las sociedades prehispánicas, posthispanicas y actuales, el clima y el ambiente ponen los mismos obstáculos a las practicas productivas validando ciertos estudios actualísticos como el que presentamos.

\section{Materiales y métodos: Isótopos estables}

Estos isótopos son incorporados en el ecosistema y en las cadenas alimentarias por los vegetales acuáticos y terrestres que a través de la fotosíntesis, transforman el dióxido de carbono $\left(\mathrm{CO}_{2}\right)$ de la atmósfera en moléculas de glucosa. Durante la fotosíntesis se produce un sesgo con respecto a las moléculas contenedoras del isótopo más pesado, con lo cual, la relación ${ }^{13} \mathrm{C} /{ }^{12} \mathrm{C}$ en la planta es diferente que aquella relación isotópica de carbono presente en la atmósfera (Ambrose 1993) 
A su vez, existen tres patrones fotosintéticos con su correlato isotópico: $\mathrm{C}^{3}$ (especies arbóreas, arbustos y la mayoría de las plantas silvestres de la Puna, $\mathrm{C}^{4}$ (maíz, algunos amarantos, caña de azúcar y sorgo) y las crasuláceas de metabolismo ácido (cactus y orquídeas, con valores que pueden hallarse tanto en la distribución $\mathrm{de}^{3} \mathrm{como}^{4}$ ) (Fernández y Panarello 199-2001). Gracias a que el grado de enriquecimiento depende del tipo de patrón fotosintético empleado por la planta, las relaciones de carbono $\left(\delta^{13} \mathrm{C}\right)$ pueden distinguir diferentes fuentes de recursos.

Entre las variables ambientales que pueden generar variación en valores $\delta^{13} \mathrm{C}$ en vegetales modernos se han señalado altitud, nivel de precipitaciones, $\delta^{13} \mathrm{CO}_{2}$ en la atmósfera; asimismo se ha encontrado un fraccionamiento, aunque mínimo entre los diferentes tejidos de una planta (Heaton 1999). Es importante aclarar que se ha registrado menor variación intraespecífica en las plantas con patrón fotosintética $C^{4}$ (Codron et al. 2005).

El nitrógeno posee dos isótopos estables, $\mathrm{el}^{14} \mathrm{~N} \mathrm{y}^{15} \mathrm{~N}$. En la biosfera, este elemento se presenta en mayor medida como gas dinitrógeno $\left(\mathrm{N}^{2}\right)$ en la atmósfera. La reserva de nitrógeno en la atmósfera tiene una composición isotópica equivalente y por lo tanto, es de $0 \%$ (Pate 1994) . La transferencia del nitrógeno inorgánico de la atmósfera $\left(\mathrm{N}^{2}\right)$ a la esfera biológica, entonces, se da a partir de organismos especializados ubicados en las raíces de las plantas fijadoras que convierten al nitrógeno gaseoso en formas posibles de ser utilizadas por las plantas (Pidwirny 2004). Dicho proceso posee escaso fraccionamiento, lo cual hace que estas plantas tengan valores similares al de la atmósfera (0\%o) (Schoeninger y De Niro 1984.). El resto de las plantas, denominadas comúnmente como "no fijadoras", toman el nitrógeno de la descomposición orgánica de sus hábitats (nitratos, amoníaco y amonio disueltos), lo que lleva a una distribución bimodal entre las plantas con respecto a este isótopo (Schoeninger y De Niro 1984). Aunque hay una superposición en los valores de las especies fijadoras y no fijadoras, estas últimas poseen, por lo general, valores significativamente más positivos (Heaton 1987), siendo el valor medio para las fijadoras de $+1 \%$, con un rango típico de -2 a $+2 \%$, mientras que en el caso de las no fijadoras es de $+3 \%$, con un rango típico de 0 a $+6 \%$ o (Pate 1994). En lo que respecta a ecosistemas modernos, es necesario resaltar el efecto de las emisiones de combustible fósil, así como también de los fertilizantes químicos. Estos han reducido en muchos casos estas diferencias (Por ejemplo, ver Hastorf y De Niro 1985).

Ahora bien, la disponibilidad de agua, considerando las precipitaciones anuales como indicador, ha sido señalada como una variable ligada a los valores obtenidos (Hartman 2011). Pues se le atribuye un mayor contenido de nitrato y amonio en los suelos salinos los cuales son característicos de los ambientes áridos (Pate 1994). Por ejemplo, en ambientes costeros y salinos de tierra adentro de Namibia y Sud África, se han encontrado vegetales con valores $4-10 \%$ más positivos que en ambientes no salinos (Heaton 1987). Amundson y colaboradores (2003) han argumentado que los ecosistemas húmedos y fríos parecerían ser más eficientes en la conservación y reciclado del nitrógeno mineral y habría una apertura mayor del ciclo del nitrógeno en los ecosistemas más secos. Por lo tanto, las pérdidas de nitrógeno por lixiviación y la transformación del nitrógeno (nitrificación, desnitrificación y volatilización del amonio) conducirían a un enriquecimiento del $\delta^{15} \mathrm{~N}$ en el nitrógeno restante en el sistema (Austin y Vitousek 1998). Por otro lado, Codron y colaboradores (2005) afirman que los suelos sódicos poseen valores altos de ${ }^{15} \mathrm{~N}$, por lo tanto no es importante la salinidad, sino la presencia de este tipo de sal. 
Sin embargo, otra variable importante que puede producir variaciones en las señales isotópicas en los vegetales es el abono animal, dado que este posee un ${ }^{15} \mathrm{~N}$ alto gracias a la pérdida preferencial de ${ }^{14} \mathrm{~N}$ en amonio volátil gaseoso. El efecto se produce cuando en la síntesis de aminoácidos vegetales interviene el nitrato convertido a partir de dicho amonio enriquecido (Choi et al. 2002).

De todos modos, aunque no hubiera fertilizantes, puede producirse enriquecimiento en los campos cultivados gracias al nitrato del suelo lixiviado por más agua y un proceso de desnitrificación (Panarello com. pers.). Sin embargo, en ambientes hiperáridos como el que estamos estudiando esto suele no ser una variable a considerar (Tchilinguirian 2008, Amudson et al. 2003).

Para el área de Antofagasta de la Sierra aún son escasos los valores isotópicos obtenidos a partir de tejidos humanos (Tabla 1). Sin embargo resulta llamativo que los valores más enriquecidos en nitrógeno, son aquellos con una cronología posterior a los 1000 años AP. Casualmente cuando se han diagnosticado mayores condiciones de aridez en la microregión.

\begin{tabular}{|c|c|c|c|c|c|c|c|c|}
\hline Sitio & Descripción & $\delta^{13} C_{\text {col }}$ & $\delta^{15} \mathbf{N}$ & $\mathrm{C} / \mathrm{N}$ & $\delta^{13} C_{a p}$ & $\delta^{13} C_{c o-a p}$ & Períodos & Comentarios \\
\hline \multirow{2}{*}{$\begin{array}{l}\text { Qda. de la } \\
\text { Cueva A1, Salar } \\
\text { de Antofalla }\end{array}$} & óseo & $-12,7$ & 8,86 & \multirow{8}{*}{. } & $-11,6$ & 1,07 & \multirow{3}{*}{$\begin{array}{l}\text { Formativo } \\
\text { Temprano }\end{array}$} & $\begin{array}{l}\text { Olivera y } \\
\text { Yacobaccio } \\
2002\end{array}$ \\
\hline & óseo & $-13,1$ & 9,64 & & $-12,9$ & 0,26 & & $\begin{array}{l}\text { Olivera y } \\
\text { Yacobaccio } \\
2002\end{array}$ \\
\hline $\begin{array}{l}\text { Cueva Cacao } \\
\text { 1a, Localidad } \\
\text { arqueológica de } \\
\text { Paicuqui }\end{array}$ & pelo & $-19,4$ & 6,61 & & & & & $\begin{array}{l}\text { Olivera com. } \\
\text { pers. }\end{array}$ \\
\hline $\begin{array}{l}\text { Bajo del Coypar } \\
\text { II }\end{array}$ & óseo & $-15,8$ & 14,97 & & $-11,7$ & 4,1 & \multirow{3}{*}{$\begin{array}{l}\text { Formativo } \\
\text { Tardío }\end{array}$} & $\begin{array}{l}\text { Olivera com. } \\
\text { pers. }\end{array}$ \\
\hline \multirow{2}{*}{$\begin{array}{l}\text { Punta de la } \\
\text { Peña } 9\end{array}$} & uña* & $-11,4$ & 11,71 & & & & & $\begin{array}{l}\text { Aranibar et } \\
\text { al. } 2007 \text { [i] }\end{array}$ \\
\hline & óseo & $-11,8$ & 11,86 & & & & & $\begin{array}{l}\text { Aranibar et } \\
\text { al. } 2007\end{array}$ \\
\hline \multirow{2}{*}{ La Alumbrera } & óseo & $-13,9$ & 10,57 & & $-12,1$ & 1,85 & \multirow{2}{*}{$\begin{array}{l}\text { Hispano- } \\
\text { indígena }\end{array}$} & $\begin{array}{l}\text { Olivera com. } \\
\text { pers. }\end{array}$ \\
\hline & óseo & $-13,2$ & 11,06 & & $-10,5$ & 2,71 & & $\begin{array}{l}\text { Olivera com. } \\
\text { pers. }\end{array}$ \\
\hline
\end{tabular}

Tabla 1. Valores isotópicos humanos disponibles para el área.

De este modo podemos hipotetizar que las cadenas tróficas en la que se insertaron los individuos o bien se encontraban enriquecidas desde su base (con pasturas bajo stress hídrico) o eran los vegetales cultivados (también) los que se enriquecieron isotópicamente debido a los procesos efectuados sobre los terrenos de cultivo (Choi et al. 2002, Hartman 2011). Es decir que tenemos al menos dos explicaciones no excluyentes entre sí para este enriquecimiento. En este sentido, es sugestivo ver a partir de la Figura 2 la existencia de una correlación entre la diferenciación isotópica de la fuente total y las proteínas en la 


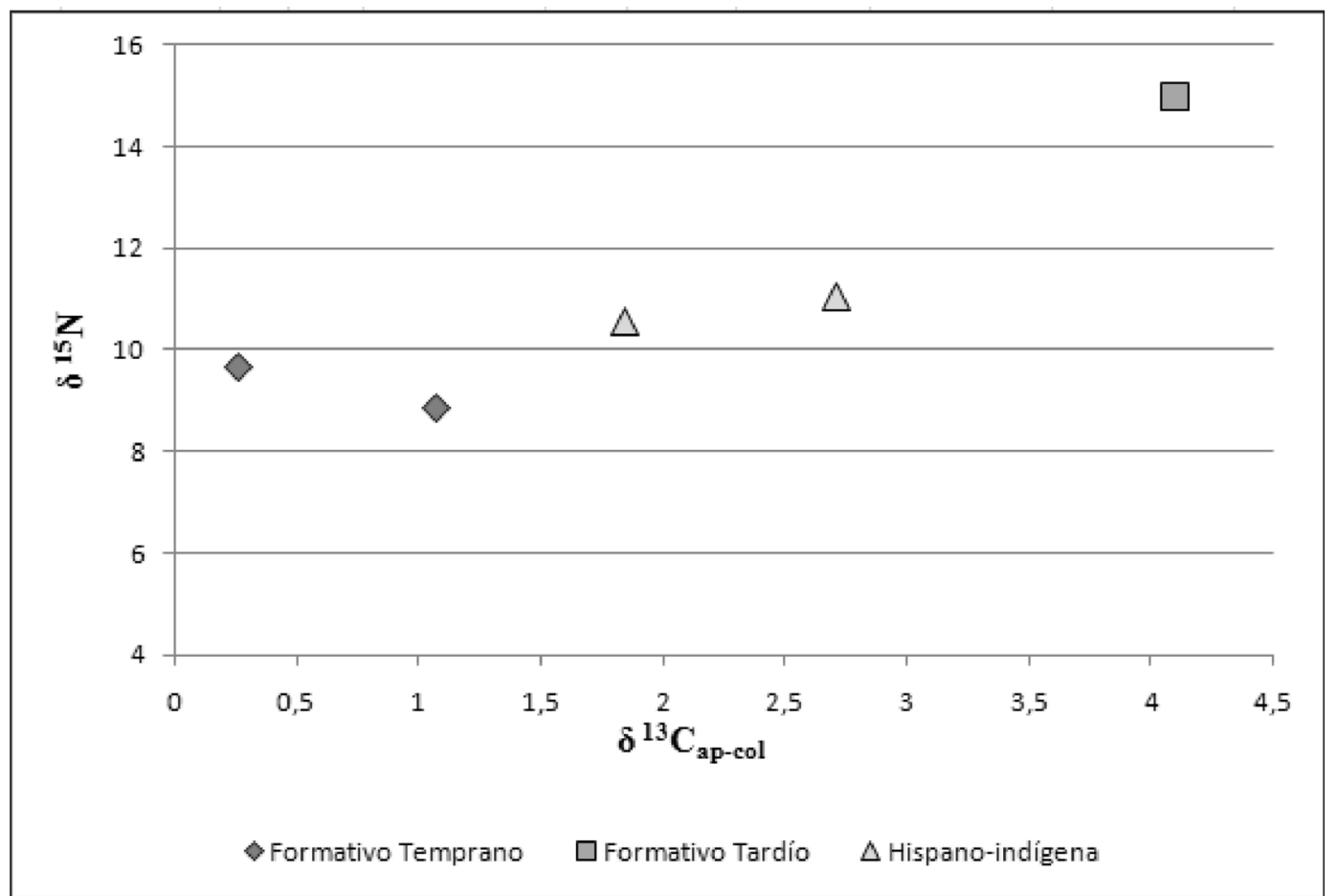

Figura. 2. Valores disponibles en fracción orgánica e inorgánica de individuos humanos hallados en la Microregión

alimentación respecto al $\delta^{15} \mathrm{~N}(\mathrm{R} 2=0,829 ; p=0,031)$, lo cual implica, a nuestro entender que las cadenas tróficas se vieron más enriquecidas en $\delta 15 \mathrm{~N}$ cuando aumentaba el componente de vegetales $\mathrm{C}^{4}$ de consumo directo en la dieta.

\section{Materiales y Técnicas empleadas}

Los ejemplares vegetales comprendidos en este trabajo fueron recolectados durante el mes de abril de 2010 y febrero de 2012. Fueron pretratados y analizados en el Instituto de Geología Isotópica y Geocronología (INGEIS). Para realizar las determinaciones isotópicas de ${ }^{13} \mathrm{C} /{ }^{12} \mathrm{C}$ y ${ }^{15} \mathrm{~N} /{ }^{14} \mathrm{~N}$, los especimenes fueron lavados en ultrasonido, secados en hormo a $60^{\circ} \mathrm{C}$ durante $24 \mathrm{hs}$ y molidos hasta reducirlos a fragmentos de $1 \mathrm{~mm}$. Se pesaron $3 \mathrm{mg}$ de muestra en cápsulas de estaño que fueron procesadas en un analizador elemental Carlo Erba EA1108 acoplado a un espectrómetro de masas para la determinación de relaciones isotópicas Thermo Scientific Delta V Advantage de flujo continuo utilizando una interfaz ConFlo IV.

\section{Materiales y Métodos: Etnoarqueología}

A raíz de la información expuesta y teniendo en consideración los diferentes sectores de la microrregión, nos propusimos realizar un trabajo etnoarqueológico. Es decir, procuramos generar información etnográfica de manera sistemática considerando sobre todo sus derivados materiales (Politis 2004). Entendemos que la arqueología puede, a partir de ella, investigar en las sociedades vivas, el rol de la cultura material y el ambiente construido por el hombre (Lane 2008), permitiendo la observación de los procesos que los afectan 
durante su producción y su uso, así como también la conformación de los contextos arqueológicos (Stark 1993). Por lo tanto, el posicionamiento que sostendremos para este trabajo es el de ubicar a la etnoarqueología como una herramienta eficaz a la hora de captar la variación de las manifestaciones culturales, permitiendo generar hipótesis acerca de las posibles estrategias para optimizar el rendimiento agrícola que operaron en el pasado. De esta manera, no perseguimos trasladar, por ejemplo, el tipo de organización familiar que prevalece en las prácticas productivas actuales, sino comprender aquellos mecanismos que tanto ayer como hoy pudieron provocar efectos similares en el registro isotópico vegetal.

Asimismo, el principal aporte de un estudio etnoarqueológico aplicado al estudio isotópico de sociedades agropastoriles y que lo hace irremplazable, es que las observaciones se realizan en contextos situados. Esta sería la diferencia de un relevamiento agrícola ganadero realizado por organismos estatales, donde se dificulta la comprensión de los hechos técnicos desde un punto de vista cultural. Sin embargo, destacamos que esta perspectiva no se ancla en los estudios Folk (a la manera de Clark en Wylie 2002). Es decir, si recurrimos al estudio de los actuales habitantes de la microrregión, no es porque se hayan demostrado lazos entre lo histórico y lo actual o se haya conservado un "substrato rural". Somos consientes del problema que existe una gran variabilidad en las estrategias productivas incluso en grupos que comparten el mismo ambiente. Es por eso que utilizamos esta información con el fin de generar hipótesis específicas para poder contrastarlas con los patrones encontrados en el registro arqueológico.

Bajo esta perspectiva, se muestrearon campos de cultivo a distintas alturas, tipos de regadío y uso de abono, todos ellos pertenecientes a familias que utilizan la agricultura como complementaria en su dieta general, dado que poseen acceso a bienes de consumo industrializados. Las diferentes respuestas respecto a las prácticas agrícolas halladas son producto principalmente del acceso a los cursos de agua y la altura.

La recolección de materiales y las entrevistas se realizaron en abril de 2010 y febrero de 2012. Nuestro interlocutores fueron los cultivadores, a los cuales se les informó sobre los objetivos de la investigación y el uso de la información adquirida. Deseamos aclarar que la identidad de los entrevistados se mantiene reservada. A continuación describiremos brevemente los casos bajo estudio:

\section{Verano 2010}

Fondo de cuenca: Entrevista 1 y 2

En este sector se registraron dos casos. Entrevistamos a una vecina de Peñas Coloradas (Entrevistado 1, E1 de ahora en más) que ubicaba sus cultivos junto a un curso de agua caudaloso, a unos 20 minutos de caminata de su casa de residencia en la villa. E1 cultiva maíz, ajo, papas y habas, pero no quínoa. Comentó que antes la consideraba como plaga aunque quizá comiencen a cultivarla dado que creció su valor económico.

El segundo caso corresponde a una entrevistada (E2) que reside también en la Villa y en cuya casa se halla la huerta, quien riega sus plantaciones con un reservorio de agua que funciona a bomba. Este, un verdadero tanque australiano de 5000 litros. Como es de esperar, el rendimiento por metro cuadrado es mayor con respecto a E1. Este hecho es particularmente notorio en el caso de maíz, pues los que se obtienen son de gran tamaño, aunque también 
se refleja en la posibilidad de cultivar una amplia variedad de frutas y verduras, incluso duraznos y uvas. Sin embargo, la entrevistada consideró que su producción no cumplía con sus expectativas y esto se debía principalmente a tres aspectos: la falta de lluvias; la solidaridad entre vecinos del "alto" (los campos a mayor altitud) que restringen la circulación del agua, amparados en la falta de una política distributiva real y; por último, los cortes de energía eléctrica que impiden el uso continuo del sistema de bomba.

Debemos destacar que en estas dos entrevistas, nombraron al agua como forma de abono.

Sectores intermedios: Entrevista 3

Como se ha observado en Laguna Blanca (Forni et al.1993) la siembra de todas las especies se realiza en recintos de tamaño variable (rastrojos) aunque en este caso no se encuentran cercados con "pirca". El impedimento para que los animales entren y los vientos y granizo tengan menos efecto sobre los cultivos se logra a partir de un entramado vegetal que incluye árboles de altura. Uno de los vecinos del Río Miriguaca introduce la siguiente técnica para optimizar sus cultivos, la cual no se encuentra en los dos casos registrados en el fondo de cuenca. Utiliza el rastrojo/corral anexo que solo contiene guano ("bostadero") (Figuras 3) al cuadro que le pertenece (ambos de aproximadamente $40 \mathrm{~m}^{2}$ ) para que el curso de agua de la acequia, pase sucesivas veces tanto por éste, como por las plantaciones. De esta manera, asegura un riego "abonado", mientras que el resto de las vecinas (su madre y su hermana), poseedoras de los cuadros anexos utilizan sólo agua.

Deseamos destacar que el área destinada al cultivo de habas es mayor que para otras especies. Esto debido principalmente a los requerimientos hídricos (y térmicos) del maíz, lógicamente escasos.

Durante nuestra estadía, se regaron los campos cada ocho días, aunque los informantes señalaron que se riega cada cuatro conforme se aproxime la época de la cosecha. La acequia se abre durante la noche, pues es usual que el caudal de agua se reduzca por evaporación al llegar al área de cultivo. Esta variable fue particularmente aguda durante nuestra estadía, aunque también se dieron fuertes granizos en la misma temporada.

Debemos destacar que este vecino, joven, no elige como lugar de residencia una casa anexa al área de plantaciones, a diferencia de su madre que reside allí la mayor parte del año. De esta manera, no puede estar atento a las vicisitudes propias de esa región tanto en la época de la siembra, como la cosecha, es decir los agentes que atentan a la prosperidad de los cultivos: granizo y pájaros (estos últimos son un agravante durante las temporadas de sequía, cuando no se encuentran disponibles plantas silvestres).

Verano 2012

Entrevista 4

Nuestro último entrevistado posee un terreno que contiene tres huertas. Pudimos registrar sólo dos de ellas. El predio se denomina Las Juntas; no depende de un sistema de turnos para el regadío, pues como su nombre lo indica, cuenta con los caudales de los Ríos Punilla y Miriguaca. Se nos aclaró que trabajan las huertas no por necesidad sino para "no perder la tradición", ya que su objetivo principal es cuidar a los animales. 


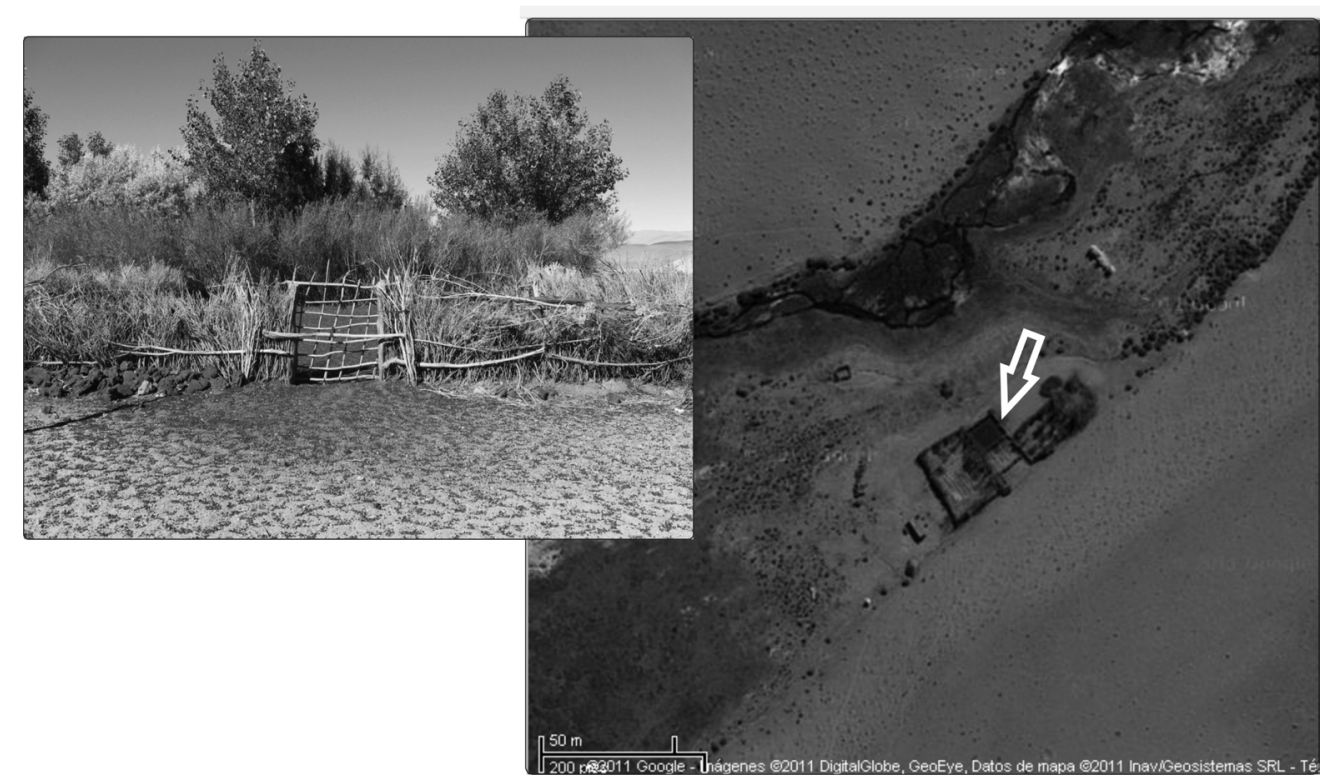

Figura. 3. Campo de guano anexo al cuadro de cultivo por donde pasa el agua de la acequia abonada e Imagen satelital del campo regado con dicho anexo

Como en el caso de la Entrevista 3 se encuentra cercada por árboles y arbustos secos para aislarla de los animales (recordemos que sus dueños viven en el pueblo y pasan a visitar no necesariamente todos los días).

La Huerta n¹: se encontraba improductiva, descansando la tierra. El terreno estaba despejado pero se podían ver papas ("wuachas", según denominó E3) que brotan sin cuidado alguno y por la misma productividad de la tierra. Posee un anexo con 4 melgas que fue conformado este año. La tierra del mismo, por lo tanto no posee abono, aunque podía verse restos de bosta en la superficie. De más está decir que al estar ubicado a lo largo de una vega, las deposiciones de llamas tapizan el área circundante y probablemente este sea el sustrato sobre el que se armó dicho anexo. El informante nos dio dos marlos de esta huerta, producto de la cosecha del 2011.

El abono que utiliza es de oveja, a las cuales se las deja dormir en la huerta (no poseen cabras, sino las usarían también; las vacas son problemáticas por el tamaño de la bosta). Con respecto al riego, si bien se realiza cada 8 días, la papa puede estar más de una semana sin riego.

Huerta 2: posee dos partes y cuenta con un corral. La diferencia es que se encuentra construido de pirca. Allí se cosechan habas, papas y maíz. Estos últimos quedaron de baja estatura dadas las heladas primaverales.

\section{Resultados de la información etnoarqueológica}

A raíz de lo descripto, una de las ventajas de trabajar en este contexto y desde una perspectiva etnoarqueológica es que perduran técnicas tradicionales para el mantenimiento de la tierra y los cultivos. Aspecto necesario dada la falta de nutrientes orgánicos $(C, N$ y P orgánico) en el suelo (Olivera y Tchilinguirian 2000), tanto en la actualidad y en el 
pasado. Por lo tanto, este caso se ajusta a lo que sugiere Politis (2004) respecto a este tipo de investigación, pues el sujeto y la fuente, dada la ausencia de uso de fertilizantes sintéticos y plaguicidas, poseen ciertas condiciones de comparabilidad, lo cual estaría garantizando los principios de la argumentación analógica.

\section{Resultados en isótopos estables sobre especies vegetales cultivadas}

En primer lugar, queremos aclarar que aquí se presenta un escenario diferente al planteado por Finucane (2007). Este autor afirmó que podría ser posible distinguir dietas basadas en maíz en contraposición con legumbres, debido a una relación negativa entre la calidad proteica y los requerimientos de abono diferencial entre ellas. Entendemos que en este caso, no podría sostenerse tal diferenciación, pues los campos son utilizados indistintamente para todos los cultivos, con lo cual, todos los recursos se encuentran bajo la mismas condiciones de abono.

Por otro lado, como ya se ha encontrado en otras investigaciones (Killian Galván et al. 2014), hallamos un ligero enriquecimiento en los valores $\delta^{13} \mathrm{C}$ y $\delta^{15} \mathrm{~N}$ entre el marlo y los granos, estando las segundas siempre más enriquecidas respecto a las primeras. Una variación mayor se encontró entre las medias de $\delta^{13} \mathrm{C}$ y $\delta^{15} \mathrm{~N}$ de las fracciones de Solanum tuberosum, hoja, 6,1\%; tallo y fruto (Tabla 3).

Durante la campaña realizada durante 2010, se obtuvo un total de 6 muestras de Zea mays. En el conjunto se destaca la menor variabilidad en los valores $\delta^{13} \mathrm{C}$ y la amplitud del rango en $\delta^{15} \mathrm{~N}$, lo cual nos alertó en un primer momento sobre la importancia de los usos de abono en entornos áridos y las implicancias en el enriquecimiento isotópico, pues lo valores más enriquecidos tuvieron lugar en los campos con menor acceso al agua. Los valores promedio para granos de los dos ejemplares regados con "pileta con bomba" en la Villa de Antofagasta de la Sierra fueron $\delta^{13} \mathrm{C}-11,2 \%$ y $\delta^{15} \mathrm{~N}+4,6 \%$, mientras para que los 4 restantes, provenientes de Río Miriguaca y Peñas Coloradas fueron $\delta 13 \mathrm{C}-10,8 \%$ y $\delta 15 \mathrm{~N}+7,1 \%$. Entonces, en consonancia con nuestras expectativas, los valores más empobrecidos en nitrógeno, eran aquellos provenientes de especimenes a menor altitud y con condiciones hídricas más favorables, pues recordemos que las huertas de Peñas Coloradas como la de Río Miriguaca se encuentran a mayor altitud respecto a la Villa (Figura 4B). Sin embargo, la muestra que fue abonada con guano de oveja, si bien muestra un valor enriquecido, no supera al valor más alto proveniente de la muestra de Peñas Coloradas (sin abono aparente y a menor altitud).

Por otro lado, esta variación no responde del mismo modo en $\delta^{13} \mathrm{C}$ y $\delta^{15} \mathrm{~N}$. En lo referente al carbono, no se hayan grandes diferencias en los valores, siendo su desvío estándar el esperado para ejemplares de la misma especie creciendo en el mismo lugar, dado que la variación típica esperada se encuentra entre los $\pm 0,8$ a \pm $1,5 \%$ o (Heaton 1999). Sin embargo, es contrario a la expectativa de hallar rangos más amplios cuando se trata de regiones bajo stress, como es el caso de los ambientes áridos (Heaton 1999).

Pero este escenario inicial se complejizó. Cuando analizamos los valores del 2012, aquellos correspondientes a Zea mays de Las Juntas, se encuentran más empobrecidos en ambas relaciones isotópicas con respecto a los medidos en el 2010, aunque lo más llamativo es el nitrógeno. A pesar de proceder de una parcela abonada, los valores son los más bajos 


\begin{tabular}{|c|c|c|c|c|c|c|c|c|c|c|c|c|}
\hline 宅 & $\stackrel{\mathbb{J}}{\frac{\pi}{4}}$ & $\stackrel{\circ}{i n}$ & 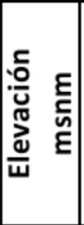 & $\begin{array}{l}\frac{0}{4} \\
\frac{0}{4} \\
\text { ய }\end{array}$ & 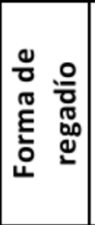 & $\begin{array}{l}\stackrel{\circ}{\circ} \\
\stackrel{\circ}{<}\end{array}$ & $\frac{\omega}{\alpha}$ & 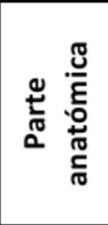 & $\overbrace{i}^{\infty}$ & 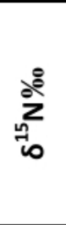 & $\frac{z}{v}$ & 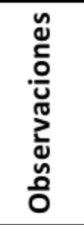 \\
\hline \multirow{13}{*}{ 옴 } & \multirow{4}{*}{$\stackrel{\stackrel{N 0}{\equiv}}{=}$} & \multirow{4}{*}{$\begin{array}{l}\underset{U}{0} \\
\mathbb{D} \\
\widetilde{J}\end{array}$} & \multirow{4}{*}{$\underset{m}{\stackrel{\infty}{m}}$} & \multirow{12}{*}{$\begin{array}{l}\text { aे } \\
\text { हे } \\
0 \\
\text { N }\end{array}$} & \multirow{4}{*}{ 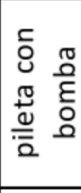 } & \multirow{10}{*}{ 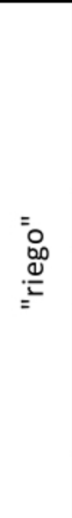 } & 25432 & grano & $-11,1$ & 6,0 & 20,1 & \multirow{4}{*}{ 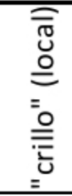 } \\
\hline & & & & & & & 25431 & tronco & $-11,9$ & 7,7 & 136 & \\
\hline & & & & & & & 25375 & grano & $-11,3$ & 3,2 & 25,5 & \\
\hline & & & & & & & 25433 & tronco & -12 & 7 & 99,2 & \\
\hline & \multirow{6}{*}{$\begin{array}{l}n \\
\frac{n}{0} \\
\frac{\pi}{0} \\
0 \\
0 \\
0 \\
0 \\
\tilde{0} \\
0 \\
0 \\
0 \\
0\end{array}$} & \multirow{4}{*}{ 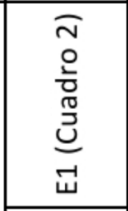 } & \multirow{6}{*}{$\underset{\text { Iิ }}{\stackrel{\Xi}{*}}$} & & \multirow{6}{*}{ 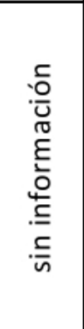 } & & 25376 & grano & $-9,7$ & 9,4 & 14,7 & \\
\hline & & & & & & & 25434 & tronco & $-10,4$ & 9,1 & 12,6 & \\
\hline & & & & & & & 25377 & grano & $-11,4$ & 6,8 & 14,9 & \\
\hline & & & & & & & 25426 & tronco & \begin{tabular}{|l|}
$-11,8$ \\
\end{tabular} & 6,7 & 36 & \\
\hline & & \multirow{2}{*}{ 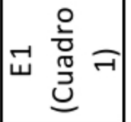 } & & & & & 25378 & grano & $-10,6$ & 3,9 & 14,1 & \\
\hline & & & & & & & 25430 & tronco & $-10,3$ & 3,8 & 14,8 & \\
\hline & \multirow{2}{*}{$\frac{\stackrel{0}{0}}{20}$} & \multirow{2}{*}{$\stackrel{m}{\Psi}$} & \multirow{2}{*}{$\begin{array}{l}\text { 음 } \\
\text { ర్ల }\end{array}$} & & \multirow{2}{*}{$\begin{array}{ll}\nabla & \mathscr{\sigma} \\
\infty & \stackrel{\pi}{\sigma}\end{array}$} & \multirow{2}{*}{ 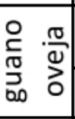 } & 25379 & grano & $-11,4$ & 8,4 & 13,9 & \\
\hline & & & & & & & \begin{tabular}{|l|}
25374 \\
\end{tabular} & tronco & $-11,8$ & 8,8 & 34,1 & \\
\hline & 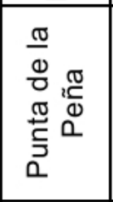 & 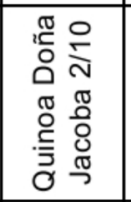 & 윯 & 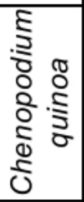 & $\bar{n}$ & $\bar{n}$ & 27633 & grano & $-24,4$ & 8,7 & 18,8 & \\
\hline \multirow{17}{*}{ 공 } & \multirow{17}{*}{ 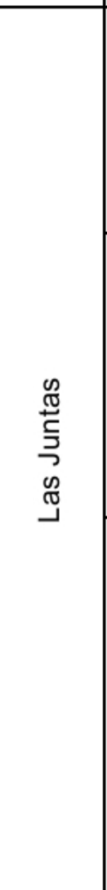 } & \multirow{4}{*}{ 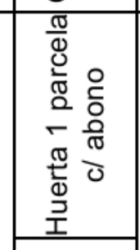 } & \multirow{17}{*}{ ల్లి } & \multirow{4}{*}{ 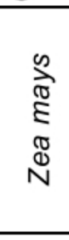 } & \multirow{17}{*}{$\begin{array}{l}\stackrel{n}{\infty} \\
E \\
0 \\
0 \\
n \\
\frac{n}{0} \\
\infty \\
\infty\end{array}$} & \multirow{17}{*}{$\begin{array}{l}\frac{0}{0} \\
\frac{1}{3} \\
0 \\
0 \\
\frac{0}{\pi} \\
\frac{0}{0}\end{array}$} & 28873 & grano & $-12,1$ & 0,7 & 28,4 & \multirow{4}{*}{ 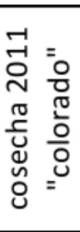 } \\
\hline & & & & & & & 28866 & tronco & \begin{tabular}{|l|}
$-11,8$ \\
\end{tabular} & $-0,8$ & 32,3 & \\
\hline & & & & & & & 28861 & \begin{tabular}{|l|} 
grano \\
\end{tabular} & $-12,0$ & 0,7 & 50,4 & \\
\hline & & & & & & & 28864 & tronco & $-12,2$ & $-1,1$ & 55,8 & \\
\hline & & \multirow{5}{*}{ 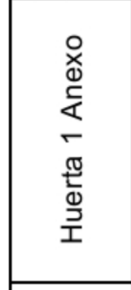 } & & & & & 28920 & hoja & $-29,4$ & 1,1 & 16,4 & \\
\hline & & & & & & & 28865 & tallo & $-28,6$ & 0,5 & 45,5 & 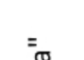 \\
\hline & & & & & & & 28867 & hoja & $-28,9$ & 4,1 & 14,1 & $\overline{\bar{O}}$ \\
\hline & & & & & & & 28922 & tallo & $-28,2$ & 1,5 & 27,6 & \\
\hline & & & & के & & & 28872 & fruto & $-26,5$ & 6,2 & 27,2 & \\
\hline & & & & $\stackrel{\circ}{\Im}$ & & & 28863 & fruto & $-24,6$ & 8,5 & 20,8 & \\
\hline & & & & E & & & 28921 & hoja & $-27,6$ & 8,3 & 24,0 & \\
\hline & & & & స్ & & & 28862 & fruto & $-25,1$ & 8,7 & 42,0 & \\
\hline & & $\pi$ & & & & & 28871 & tallo & $-27,1$ & 7,4 & 27,2 & 5 \\
\hline & & $\stackrel{\bar{\Phi}}{2}$ & & & & & 28874 & hoja & $-28,0$ & 9,2 & 18,4 & 离 \\
\hline & & & & & & & 28869 & fruto & $-25,7$ & 7,4 & 34,3 & \\
\hline & & & & & & & 28868 & tallo & $-27,4$ & 5,7 & 28,0 & \\
\hline & & & & & & & 28875 & hoja & $-28,7$ & 7,5 & 20,0 & \\
\hline
\end{tabular}

Tabla 2. Valores $\delta^{13} \mathrm{C}$ y $\delta^{15} \mathrm{~N}$ de vegetales cultivados pertenecientes a diferentes sectores de Antofagasta de la Sierra. 


\begin{tabular}{|c|c|c|c|c|c|c|}
\hline & \multicolumn{3}{|c|}{$\delta^{13} \mathbf{C} \%$} & \multicolumn{3}{c|}{$\delta^{15} \mathbf{N} \%$} \\
\hline Zea mays & grano & tronco & & grano & tronco & \\
\cline { 1 - 3 } \cline { 5 - 6 } Media & $-11,2$ & $-11,5$ & & 4,8 & 5,1 & \\
\cline { 5 - 6 } Mediana & $-11,3$ & $-11,8$ & & 4,9 & 6,8 & \\
\hline D.E. & 0,7 & 3,3 & & 0,7 & 4,1 & \\
\hline $\begin{array}{c}\text { Solanum } \\
\text { tuberosum }\end{array}$ & hoja & tallo & tubérculo & hoja & tallo & tubérculo \\
\hline Media & $-28,5$ & $-27,8$ & $-25,5$ & 6,05 & 3,7 & 7,7 \\
\hline Mediana & $-28,7$ & $-27,8$ & $-25,4$ & 7,5 & 3,5 & 7,9 \\
\hline D.E. & 0,7 & 0,6 & 0,8 & 3,7 & 3,3 & 1,1 \\
\hline
\end{tabular}

Tabla 3. Comparación de las mediciones isotópicas efectuadas en las distintas partes de las plantas.

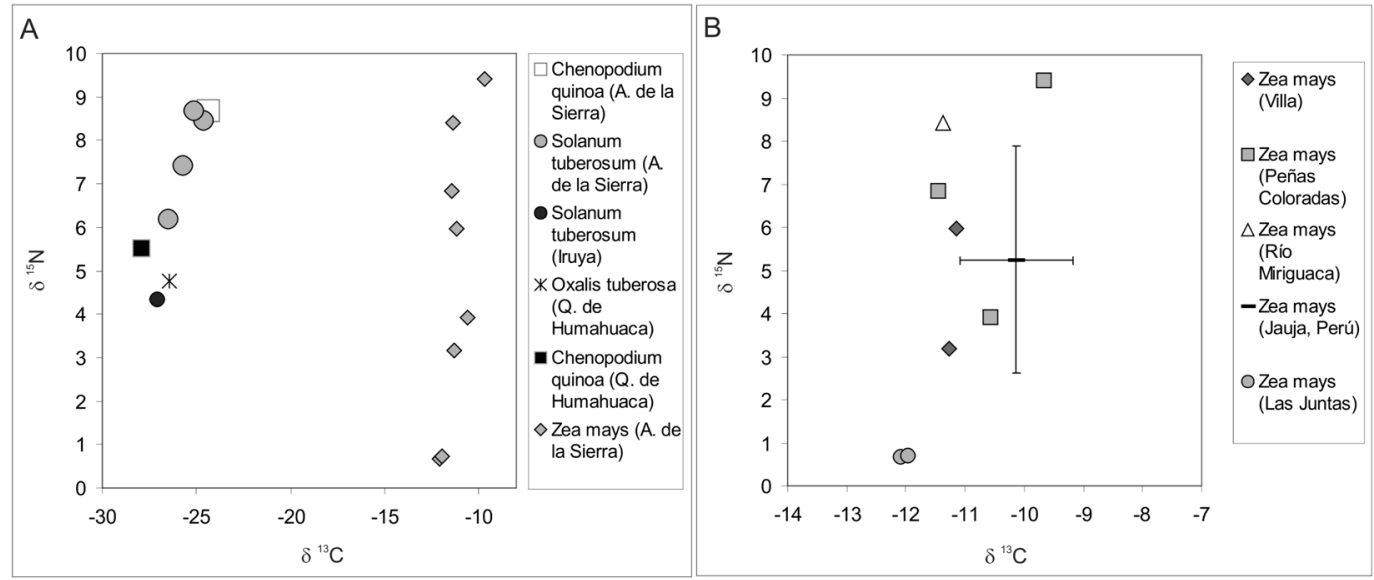

Figura 4A. Valores de vegetales cultivados $\delta^{13} \mathrm{C}$ y $\delta^{15} \mathrm{~N}$ provenientes de Argentina (Quebrada de Humahuaca, Jujuy e Iruya, Salta). 4B. Valores de Zea mays de las diferentes huertas de Antofagasta de la Sierra y Jauja (Perú).

de la microrregión. La ausencia de stress hídrico (recordemos que estas huertas se riegan mediante dos cursos se agua) parecen haber influido en el maíz, pero no en los valores en Solanum tuberosum ya que estos son bastante altos.

Para entender la dispersión de valores intraespecífica, comparamos los resultados con valores procedentes de un área ecológicamente diferente como es la Quebrada de Humahuaca y valles occidentales. Entre aquellos especimenes con patrón fotosintético $\mathrm{C}^{3}$ parece no haber solapamiento si comparamos los tubérculos y quínoa procedente de puna y el resto de los vegetales de Quebrada de Humahuaca (Figura 4A). Así mismo y dado que aún no se han publicado valores actuales para Zea mays en la región, nos remitiremos a los publicados por Hastorf y De Niro (1985) en Jauja, Perú. Aunque los datos también son escasos, consideramos que la comparación resulta pertinente. A partir de la dispersión de los valores (Figura 4B), 
podemos observar que aquellos en puna de Zea mays tienden a ocupar un rango mayor a los de Jauja, sobre todo en lo que refiere al nitrógeno, no tanto así respecto al carbono.

\section{Discusión y consideraciones finales}

El relevamiento de información etnográfica en la microrregión de Antofagasta de la Sierra, surgió con el objetivo de observar bajo condiciones controladas los efectos del abono en los valores ${ }^{13} \mathrm{C} y \delta^{15} \mathrm{~N}$ de cultígenos en desiertos de altura. Esta investigación se vio motivada por los valores enriquecidos de $\delta^{15} \mathrm{~N}$ en el registro óseo humano en contextos arqueológicos de la puna argentina (Pérez y Killian Galván 2011) y, en particular, aquellos procedentes de Antofagasta de la Sierra. Aunque son escasas aún las mediciones efectuadas sobre tejidos humanos, resulta llamativo que los valores más enriquecidos en nitrógeno, son aquellos con una cronología posterior a los 1000 años AP (recordemos un individuo con un valor $\delta^{15} \mathrm{~N}=+14,9 \%$ ). Casualmente cuando se han diagnosticado mayores condiciones de aridez en la microregión pero también un importante desarrollo en la intensificación agrícola (Olivera y Vigliani 2000-2002). Por lo tanto, hipotetizamos que dicho valor pudo deberse no solo al consumo de más proteínas animales, sino a la influencia de variables asociadas a la aridez del área sobre los vegetales.

En lo que respecta al registro isotópico de los vegetales cultivados en la microregión, nuestras expectativas se cumplieron parcialmente, dado que, por un lado, existe un amplio rango en los valores $\delta^{15} \mathrm{~N}$ procedentes de altitudes similares, mientras que por el otro, el acceso al agua sólo parece reflejarse en los valores de nitrógeno de los ejemplares de Zea mays (Figura 5).

Probablemente hallemos una correlación entre los valores de nitrógeno y la altitud entre las huertas ubicadas en las zonas más extremas de los sectores intermedios, como lo muestra el valor de Chenopodium quinoa de Punta de la Peña. Por otro lado, tampoco resulta clara la relación entre los valores isotópicos y el abono. Entonces, no solo es necesaria una ampliación del muestreo, sino iniciar análisis de suelos sobre los campos de cultivo considerados. Y esto, ¿por qué?: pues porque quizás existan

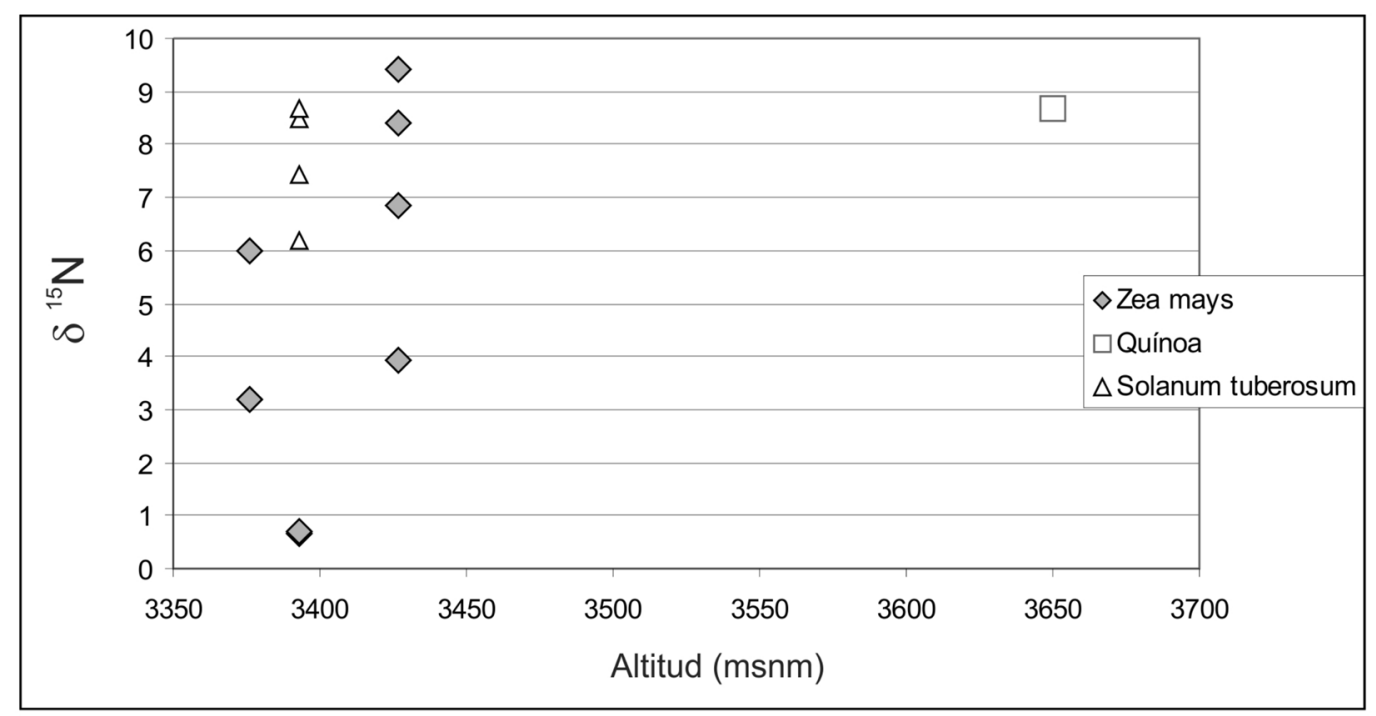

Figura 5. Vegetales cultivados de Antofagasta de la Sierra discriminados por su altitud. 
diferencias en la disponibilidad de nitratos $\left(\mathrm{NH}_{4}{ }^{+}\right)$y amonio $\left(\mathrm{NO}_{3}^{-}\right)$en cada una de las huertas estudiadas, lo cual repercutiría en el enriquecimiento de la señal isotópica del nitrógeno (Amundson et al. 2003).

Pero aunque expliquemos por qué las relaciones isotópicas no se mantienen constantes al interior de una misma especie, resta abordar el salto inferencial que se realiza para interpretar estos valores en relación con las paleodietas humanas. Dado que en el presente muestreo hallamos un valor $\delta^{15} \mathrm{~N}+9 \%$ o de Zea mays, consideramos que el componente vegetal de la dieta durante la intensificación agrícola puede explicar el enriquecimiento en $\delta^{15} \mathrm{~N}$ hallado en humanos. Resulta fundamental entonces, generar más datos para descartar que este sea simplemente un valor extremo.

Sin duda, los valores isotópicos en pasturas y camélidos actuales y arqueológicos, cuyo análisis se encuentra en proceso (Grant com. pers.), serán útiles para comprender de manera global la ecología isotópica del área.

En síntesis, este trabajo inicial apuntó a comprender los múltiples agentes que pueden actuar sobre los vegetales cultivados en las huertas de Antofagasta de la Sierra y cómo ello puede repercutir en los valores isotópicos de los mismos. Recordamos que esto es particularmente importante para comprender los resultados en nitrógeno de individuos hallados en sitios arqueológicos del área. Su importancia radica en los problemas de equifinalidad que frecuentemente debemos afrontar al discutir la "carnivoridad" vs. la "herviboridad" de las poblaciones del NOA, en particular de la Puna argentina a partir de las dichas relaciones isotópicas. Podemos hipotetizar, entonces, que la variabilidad en humanos no responde necesariamente a la inclusión de más o menos proteína animal (Schoeninger y De Niro 1984) sino ser consecuencia también del componente vegetal de la dieta. Esto, ya sea por consumo directo de plantas cultivadas o la variabilidad intrínseca del componente primario de las cadenas tróficas, es decir, las pasturas consumidas por los herbívoros. Sin embargo, somos consientes que el nitrógeno que analizamos en el colágeno proviene fundamentalmente del componente proteico de la dieta, con lo cual los vegetales tienen una influencia menos jerarquizada que los productos cárnicos en la estimación paleodietaria (Krueger y Sullivan 1984).

Finalmente, este trabajo apuntó a concebir a la etnoarqueología como una puerta de entrada para pensar las diferentes formas de optimizar los recursos en zonas áridas. El sistema de abono que no hallamos en nuestra revisión bibliográfica del área, consistente en el enriquecimiento del agua mediante su paso por un "bostadero" pudo ser parte de una estrategia doméstica para el uso eficiente del agua también en el pasado. Este esquema argumentativo forma parte de aspectos específicos de lo que pudo ser la producción y apunta a generar los primeros pasos en la integración de información actual en la comprensión de los efectos antrópicos sobre la producción agrícola y sus consecuencias en la ecología isotópica en Antofagasta de la Sierra y un aporte a los ambientes áridos en general.

\section{Epílogo}

La visita a los cultivadores dos años después de iniciada nuestra investigación nos ha permitido dimensionar cuán diferentes pueden ser las condiciones para la agricultura en este sector de la puna argentina. En el caso de la familia de E1, optaron por desarmar las 
huertas por la quema accidental del perímetro de árboles que circundaba los cultivos y los cultivos en sí. Por otro lado, los terrenos que lograron salvarse, tampoco se utilizaron para la producción dado que el intenso granizo destruyó gran parte de las plantas.

Por otro lado, E2 en 2011 no pudo sembrar por varias razones: faltó una buena administración del agua, hasta enero no hubo lluvias, con lo cual se les pasó el período de siembra. Por otro lado, no consiguió peones redituables ("no quieren trabajar"), lo que hizo que la inversión no valiera la pena.

Nuestro paso por Las Juntas sin embargo nos dio la pauta que debíamos tener una posición activa frente a estos problemas. Los mismos vecinos nos solicitaron la búsqueda de soluciones para sus problemas agrícolas, con la cual pusimos en marcha el diseño de un proyecto interdisciplinario en pos de la búsqueda de la optimización de las cosechas. Esperamos poder ponerlo en funcionamiento en el futuro.

Agradecimientos: Agradecemos a las familias de Antofagasta de la Sierra que colaboraron aportando información en las entrevistas; a Patricia Escola por permitirnos realizar este trabajo en el marco de sus campañas arqueológicas; a Pilar Babot por cedernos la muestra de quínoa analizada; a Lorena Grana y Alejandra Elías por su ayuda en las tareas de campo; a Marcelo Morales y otro/a evaluador/a anónimo/a por sus comentarios a una primera versión de este trabajo. Esta investigación se realizó en el marco de las becas internas doctorales Tipo I y II de CONICET de la primera autora.

\section{Notas}

1 En la notación delta, $\delta 13 C$, representa la diferencia entre la medición de la relación isotópica que nos interesa y la relación isotópica de un estándar que en el caso del carbono, es el carbonato V-Pee Dee Belemnite. Debido a que esta diferencia es muy pequeña, dicha tasa es expresada como partes por mil (\%o), siguiendo la siguiente ecuación:

$$
\delta^{13} C=\left(\frac{{ }^{13} C /{ }^{12} C}{\text { Muestra }}-1\right) \cdot 1000
$$

2 La relación de isótopos de nitrógeno son analizados y expresados también como valores $\delta$ por mil, utilizándose la siguiente fórmula:

$$
\delta^{15} \mathrm{~N}=\left[\frac{\left({ }^{15} \mathrm{~N} /{ }^{14} \mathrm{~N}\right)_{\text {muestra }}}{\left({ }^{15} \mathrm{~N} /{ }^{14} \mathrm{~N}\right)_{\text {AIR }}}-1\right] \times 1000
$$

\section{Bibliografía}

Ambrose, S. H.

1993. Isotopic analysis of paleodiets: Methodological and interpretive considerations (ed. Por M. K. Sandford), Investigations of ancient human tissue. Chemical analysis in anthropology, pp. 59-130. Pensylvania, Gordon and Breach Science Publishers.

Amundson, R., A.T. Austin; E.A.G. Schuur, K. Yoo, V. Matzek, C. Kendall, A. Uebersax, D. Brenner and W.T. Baisden

2003. Global patterns of the isotopic composition of soil and plant nitrogen. Global biogeochemical cycles, 17(1): 1031. 
Araníbar J., M. López Campeny, M. G. Colaneri, A. S. Romano, S. A. Macko y C. A. Aschero. 2007. Dieta y Sociedades Agropastoriles: análisis de isótopos estables de un sitio de la Puna Meridional Argentina (Antofagasta de la Sierra, Catamarca). Comechingonia 10: 29-48.

Aschero, C

2000. El poblamiento del territorio. En Nueva Historia Argentina: Los pueblos originarios y la conquista, dirigido por M. Tarragó, Tomo I, pp. 18-59. Sudamericana, Buenos Aires.

Austin, A. T. y P. M. Vitousek

1998. Nutrient dynamics on a rainfall gradient in Hawai i. Oecologia 113: 519-529.

Cerri, D.

1903. El territorio de los Andes (República Argentina). Reseña geográfica descriptiva, Editorial Universidad Nacional de Jujuy, Serie: Jujuy en el Pasado.

Choi, W., S. Lee, H. Ro, K. Kim y S.Yoo

2002. Natural $15 \mathrm{~N}$ abundances of maize and soil amended with urea and composted pig manure. Plant and Soil 245: 223-232.

Codron, J., Codron, D., Lee-Thorp, J. A., Sponheimer, M., Bond, W. J., de Ruiter, D., y R. Grant. 2005 Taxonomic, anatomical, and spatio-temporal variations in the stable carbon and nitrogen isotopic compositions of plants from an African savanna. Journal of Archaeological Science, 32(12), 1757-1772.

Craig, $\mathrm{H}$.

1957. The natural distribution of radiocarbon and the exchange time of carbon dioxide between atmosphere and sea. Tellus, 9(1), 1-17.

Finucane, B. C.

2007. Mummies, maize, and manure: Multi-tissue stable isotope analysis of late prehistoric human remains from the Ayacucho Valley, Peru. Journal of Archaeological Science, 34(12), 2115-2124.

Forni, F. M. I. Tort, D. Jimenez y L. Pessina.

1993. Estudios socio-antropológicos de la Puna catamarqueña, Centro de Estudios de Investigaciones Laborales, CONICET, Buenos Aires, Argentina. p. 47. Disponible http:// bibliotecavirtual.clacso.org.ar/ar/libros/argentina/ceil/forni.rtf.

García S. P. y D. S. Rolandi

1999. Viajes comerciales, intercambio y relaciones sociales en la población de Antofagasta de la Sierra (Puna meridional, Argentina). En: Propuestas para una Antropología Argentina V. (ed. por C. E. Berbeglia) Ed. Biblos, Buenos Aires.

García S. P, D. S. Rolandi y D. E. Olivera

2000. Puna e Historia. Antofagasta de la Sierra, Catamarca. Ed. Del Tridente, Buenos Aires.

García, S., D. S. Rolandi de Perrot, M. López, y P. Valeri

2002a "Alfa", vega y hortaliza. Riego y siembra en Antofagasta de la Sierra, Puna catamarqueña. Relaciones de la Sociedad Argentina de Antropología, 27. 
García, S. P., P., Valeri, D. Rolandi, y M. López

2002b. Viajes comerciales de intercambio en el departamento de Antofagasta de la Sierra, Puna meridional argentina: pasado y presente. Redes: Revista hispana para el análisis de redes sociales, (2), 5 .

Grana, L. G.

2013. Arqueología y paleoambiente: dinámica cultural y cambio ambiental en sociedades complejas de la puna meridional argentina. Tesis Doctoral inédita. Facultad de Filosofía y Letras, UBA.

Hartman, G.

2011. Are elevated $\delta^{15} \mathrm{~N}$ values in herbivores in hot and arid environments caused by diet or animal physiology?. Functional Ecology, 25(1), 122-131.Hastorf, C. A. y M. J. De Niro 1985 Reconstruction of prehistoric plant production and cooking practices by a new isotopic method. Nature 315: 489-491.

Heaton, T. H. E.

1987 The ${ }^{15} \mathrm{~N} /{ }^{14} \mathrm{~N}$ ratios of plants in South Africa and Namibia: relationship to climate and coastal/saline enviroments. Oecologia 74, 2: 236-246.

Heaton, T. H. E.

1999 Spatial, Species, and Temporal Variations in the ${ }^{13} \mathrm{C} /{ }^{12} \mathrm{C}$ Ratios of $\mathrm{C}^{3}$ Plants: Implications for Palaeodiet Studies. Journal of Archaeological Science, 26, 1: 637-649.

INDEC.

2010. Información Estadística. [En Línea]. Argentina: Instituto Nacional de Estadísticas y Censos. <http:/ / http:/ / www.indec.gov.ar> (06 de mayo de 2012)

Killian Galván, V. A. y C. T. Samec.

2012. A cada uno su verdad culinaria: Patrones paleodietarios y variables ambientales en el NOA. En: Entre Pasados y Presentes 3. Estudios contemporáneos en Ciencias Antropológicas (N. Kuperszmit, L. Mucciolo, T. Lagos Mármol y M. Sacchi: Eds.). Pp. 487-508. Ed. MNEMOSYNE, Buenos Aires.

Killian Galván, V. A., D. E. Olivera y E. Gallegos.

2012. Una aproximación isotópica al consumo del maíz en la Localidad Arqueológica Río Doncellas (Dpto. de Cochinoca, Prov. de Jujuy) (Ed. por P. Babot, F. Pazzarelli y M. Marschoff, Las manos en la masa: arqueologías y antropologías de la alimentación en Sudamérica. Pp 319-338. Ed. Corintios 31, Córdoba.

Killian Galván, V. A., N. Oliszewski, D. E. Olivera y H. O. Panarello.

2014. Intraspecific Variability in the $\delta^{13} \mathrm{C}$ and $\delta^{15} \mathrm{~N}$ Values of Archaeological samples of Zea mays Cobs (Northweastern Argentinean Puna). En: D. M. Kligmann y M. Morales (Comp.) British Archaeological Reports, Internacional Series (Editorial Archaeopress, UK). En prensa.

Krueger, H. W., y Sullivan, C. H.

1984. Models for carbon isotope fractionation between diet and bone. Stable isotopes in nutrition, 258, 205-220. 
Lane, $P$.

2008. Present to past: Ethnoarchaeology. Handbook of material culture (ed. por C Tilley, W. Keane, S. Küchler, M. Rowlands y S. Spyer), pp. 402-424. Sage, Los Angeles.

Martínez, J.

2003. Ocupaciones Humanas Tempranas y Tecnología de Caza en la Microregión de Antofagasta de la Sierra (10000-7000 AP). Tesis Doctoral. Facultad de Ciencias Naturales e Instituto Miguel Lillo, Universidad Nacional de Tucumán. S.M. de Tucumán.

Olivera, D. y P. Tchilinguirian

2000. De aguas y tierras: Aportes para la reactivación de campos agrícolas arqueológicos en la Puna Argentina. Relaciones XXV: 99-118.

Olivera, D. E. y H. D. Yacobaccio

2002. Estudios de Paleodieta en Poblaciones Humanas de los Andes del Sur a Través de Isótopos Estables. Actas del V Congreso Nacional de Paleopatología, Alcalá la Real, España.

Olivera, D.E.y S. Vigliani.

2000-2002. Proceso cultural, uso del espacio y producción agrícola en la Puna meridional argentina. Cuadernos del INAPL 19: 459-481.

Olivera, D., S. Vigliani, A. Elías, L. Grana y P. Tchilinguirian 2003-2005. La ocupación Tardío-Inca en la Puna Meridional: El sitio Campo Cortaderas. Cuadernos del Instituto Nacional de Antropología y Pensamiento Latinoamericano, 20: 257-277.

Oliszewski, N. y D. E. Olivera

2009. Variabilidad racial de macrorestos arqueológicos de Zea mays (Poaceae) y sus relaciones con el proceso agropastoril en la puna Meridional Argentina (Antofagasta de la Sierra, Catamarca) Darwiniana, 47, 1: 76-9.

Paoli, H., Bianchi, A. R., Yañez, C. E., Volante, J. N., Fernández, D. R., Mattalía, M. C., y Noé, Y. E.

2002. Recursos Hídricos de la Puna, valles y Bolsones áridos del Noroeste Argentino. Convenio INTA EEA Salta-CIED.

Pate, F. D.

1994. Bone Chemistry and Paleodiet. Journal of Archaeological Method and Theory 1: 161-209.

Pérez M. y V. A. Killian Galván.

2011 “Doncellas (Puna Septentrional, Jujuy, Argentina): Nuevos enfoques a partir del estudio cerámico y el análisis paleodietario". Estudios Atacameños 42: 79-100.

Pidwirny, M.

2006. The Nitrogen Cycle. Fundamentals of Physical Geography, 2nd Edition. Fecha de visita: http://www.physicalgeography.net/fundamentals/9s.html 
Politis, G. G.

2004. Tendencias de la Etnoarqueología en América Latina. En: Teoría Arqueológica en América del Sur. Ed. por G. G. Politis y R. D. Peretti, pp. 85-117. INCUAPA-UNICEN, Olavarría.

Salminci, P. M.

2010. Configuración espacial y organización social: análisis de acceso en la Alumbrera (Período Tardío, puna meridional, Argentina). Arqueología, 16: 105-124.

Schoeninger, M. J., y DeNiro, M. J.

1984. Nitrogen and carbon isotopic composition of bone collagen from marine and terrestrial animals. Geochimica et Cosmochimica Acta 48(4), 625-639.

Stark, M.

1993. Re-fitting the "cracked and broken façade": the case of empiricism in post-processual ethnoarchaeology. En: Archaeology Theory: who sets the agenda?, pp. 93-104. Cambridge University Press, Cambridge.

Tchilinguirian, $P$.

2008. Paleoambientes Holocenos en la Puna Austral, Provincia de Catamarca (27ㅇ): Implicancias Geoarqueológicas. Tesis Doctoral inédita, Facultad de Ciencias Exactas y Naturales. Universidad de Buenos Aires.

Tchilinguirian, P. y D. E. Olivera

2000. De aguas y tierras: aportes para la reactivación de campos agrícolas arqueológicos en la Puna Argentina. Relaciones 25: 99-118

Wylie, A.

2002. The reaction against analogy. En: Thinking of Things: Essays in the Philosophy of Archaeology, University of California Press, Berkeley: 136-153. 